\title{
Blood Donation Rates in the United States 1999-2016: From the National Health and Nutrition Examination Survey (NHANES)
}

John P. Twarog, BS, MPH, Ashley T. Russo, BS, MS, Tara C. McElroy, BS, MPH, Elizabet Peraj, BA, Martin P. McGrath, BS, and Austin C. Davidow, BS

Background: Although there have been analyses on the qualities associated with individuals who chose to repeatedly donate blood, there is little known about national blood donation rates in the United States. To address this lack of information, this article uses data from the National Health and Nutrition Examination Surveys (NHANES) to assess changes in the national rates of blood donation among adults aged 20 years and older.

Methods: Data was collected from 49,512 US adults aged 20 years and older who were surveyed from 1999 to 2016 through the NHANES. Individuals selected for inclusion in NHANES underwent an in-home interview, where they were asked whether or not they participated in blood donation in the past 12 months. Data were analyzed with SAS and Wald-chi square tests were used to assess trends in recent blood donations.

Results: The overall recent blood donation rate has hovered around 6\% since 1999, with no significant change during that time period. Over the last 2 decades, the percentage of individuals aged 20 to 29 years with a recent blood donation has increased significantly. During the same time period, the percentage of individuals aged 30 to 39 years and individuals with a 4-year college degree or greater with a recent blood donation decreased significantly.

Conclusions: Although the national blood donation rate has not changed significantly, significant changes in donation rates have occurred among a number of US subpopulations. ( $J$ Am Board Fam Med 2019;32:746-748.)

Keywords: Blood Donors, Blood Transfusion, Hospitalists, Nutrition Surveys, Population Health

Clinicians have historically relied on members of the local community to voluntarily donate blood to be used in necessarily medical situations for those in need of a blood transfusion. ${ }^{1}$ Although there have been analyses on the qualities associated with individuals who chose to repeatedly donate blood, ${ }^{2}$ there is little known about national blood donation rates in the United States. This article uses data from the National Health and Nutrition Examination Surveys (NHANES) conducted from 1999 to

This article was externally peer reviewed.

Submitted 18 December 2018; revised 11 February 2019; accepted 17 February 2019.

From the New York College of Podiatric Medicine, New York, NY (JPT, ATR, TCM, EP, MPM, ACD).

Funding source: No external funding for this manuscript.

Financial disclosure: The authors have indicated they have no financial relationships relevant to this article to disclose.

Conflict of interest: The authors have indicated they have no potential conflicts of interest to disclose.
2016 to assess changes in the national rates of blood donation among adults aged 20 years and older.

\section{Methods}

The NHANES is an ongoing, stratified, multistage probability sample of the US noninstitutionalized population. Conducted biannually by the Centers for Disease Control and Prevention (CDC), NHANES takes place across the United States and is designed to assess the health and nutritional status of the general population. ${ }^{3}$ Individuals se-

Contributors statement: Study Design: Twarog and Peraj, Statistical Analysis: Twarog, Drafting of the manuscript: Twarog, Peraj, Davidow, McGrath, Critical revision and editing of the manuscript: Twarog, Peraj, Davidow, McGrath, Russo, and McElroy, Approval of final manuscript for publication: Twarog, Peraj, Davidow, McGrath, Russo, and McElroy. Corresponding author: John Twarog, BS, MPH, New York College of Podiatric Medicine, New York, NY 10035 (E-mail: jtwarog2021@nycpm.edu). 
Table 1. Trends in Recent Blood Donations across the United States Adult Population, 1999 to 2016

\begin{tabular}{|c|c|c|c|c|c|c|}
\hline Category & Unweighted $\mathrm{N}^{* \dagger}$ & Weighted \% (SE) ${ }^{\dagger}$ & 1999 to 2004 & 2005 to 2010 & 2011 to 2016 & $P$ Value $^{\ddagger}$ \\
\hline \multicolumn{7}{|l|}{ Donated last 12 months } \\
\hline No & 37,778 & $94.1(0.2)$ & & & & \\
\hline Yes & 1,674 & $5.9(0.2)$ & $6.2(5.6-6.8)$ & $6.2(5.4-6.9)$ & $5.5(5.9-6.2)$ & 0.29 \\
\hline \multicolumn{7}{|l|}{ Sex } \\
\hline Male & 19,268 & $48.6(0.2)$ & $6.4(5.6-7.2)$ & $6.7(5.8-7.6)$ & $6.0(5.1-6.8)$ & 0.50 \\
\hline Female & 20,184 & $51.4(0.2)$ & $5.9(5.1-6.8)$ & $5.7(4.9-6.5)$ & $5.1(4.3-6.0)$ & 0.39 \\
\hline \multicolumn{7}{|l|}{ Age } \\
\hline 20 to 29 years & 6,954 & $19.0(0.4)$ & $5.9(4.6-7.2)$ & $6.5(5.2-7.9)$ & $8.4(7.1-9.7)$ & 0.02 \\
\hline 30 to 39 years & 6,629 & $18.7(0.3)$ & $7.0(5.5-8.5)$ & $6.0(4.8-7.2)$ & $4.2(3.3-5.2)$ & 0.0057 \\
\hline 40 to 49 years & 6,658 & $20.3(0.3)$ & $7.8(6.3-9.3)$ & $7.1(5.6-8.7)$ & $5.6(3.9-7.3)$ & 0.14 \\
\hline 50 to 59 years & 5,815 & $18.0(0.3)$ & $6.9(5.6-8.3)$ & $7.7(5.9-9.5)$ & $7.0(5.3-8.6)$ & 0.76 \\
\hline 60 years & 13,396 & $24.0(0.4)$ & $3.3(2.5-4.1)$ & $4.9(3.0-4.9)$ & $3.4(2.5-4.2)$ & 0.58 \\
\hline \multicolumn{7}{|l|}{ Race/ethnicity } \\
\hline Non-Hispanic white & 18,672 & $70.6(1.1)$ & $7.0(6.3-7.8)$ & $7.2(6.3-8.2)$ & $6.5(5.6-7.4)$ & 0.46 \\
\hline Non-Hispanic black & 7,982 & $10.7(0.6)$ & $3.8(2.8-4.8)$ & $3.1(2.4-3.8)$ & $3.8(2.9-4.7)$ & 0.40 \\
\hline Mex-American or Hispanic & 9,863 & $12.7(0.8)$ & $3.4(2.1-4.7)$ & $3.3(2.6-4.1)$ & $3.3(2.5-4.1)$ & 0.99 \\
\hline Other & 2,935 & $6.0(0.3)$ & $5.8(2.7-9.0)$ & $4.6(2.5-6.6)$ & $3.8(2.5-5.0)$ & 0.44 \\
\hline \multicolumn{7}{|l|}{ Household income } \\
\hline$\leq 130 \%$ & 12,100 & $21.1(0.6)$ & $2.6(1.8-3.4)$ & $2.9(2.2-3.6)$ & $2.9(2.2-3.7)$ & 0.79 \\
\hline $130 \%$ to $\leq 185 \%$ & 5,356 & $10.9(0.3)$ & $3.5(2.3-4.7)$ & $3.2(2.2-4.3)$ & $4.0(2.5-5.5)$ & 0.70 \\
\hline$>185 \%$ & 21,996 & $68.0(0.8)$ & $7.7(6.8-8.6)$ & $7.5(6.7-8.4)$ & $6.7(5.7-7.6)$ & 0.25 \\
\hline \multicolumn{7}{|l|}{ Education } \\
\hline High school or less & 19,685 & $40.6(0.8)$ & $3.5(2.8-4.2)$ & $3.6(2.8-4.3)$ & $2.8(2.1-3.6)$ & 0.31 \\
\hline College/AA & 11,165 & $31.3(0.4)$ & $6.5(5.5-7.5)$ & $6.9(5.6-8.3)$ & $6.5(5.4-7.6)$ & 0.84 \\
\hline College graduate & 8,602 & $28.1(0.8)$ & $10.7(8.8-12.6)$ & $9.4(8.0-10.9)$ & $7.5(6.2-8.8)$ & 0.0165 \\
\hline
\end{tabular}

SE, standard error; AA, associate of arts.

*The sample sizes were unweighted, but the percentages were generated as weighted estimates.

${ }^{\dagger}$ Unweighted $\mathrm{N}$ and weighted \% represent the breakdown of the entire study population. Subsequent columns represent the percentage of people who donated blood during the indicated time period.

${ }^{\ddagger}$ Wald $\chi^{2}$ tests were used to determine changes in the prevalence of recent blood donations for each subgroup. The values in bold are significant.

lected for inclusion in NHANES undergo an inhome interview, followed by a physical examination in a CDC Mobile Examination Center. Information on the NHANES response rates can be found here in the cited reference. ${ }^{4}$ The data from NHANES have been deidentified by the CDC, which gave our study exemption from New York College Podiatric Medicine institutional review board approval. We collected data on 49,512 US adults aged 20 years and older who were surveyed for NHANES from 1999 to 2016. After excluding individuals with missing data on history of recent blood donation $(\mathrm{n}=$ 6560), education $(\mathrm{n}=58)$, and household income status ( $\mathrm{n}=3442$ ), our final study population was 39,452 individuals ( $80 \%$ of the initial population).

\section{Recent Blood Donation}

During the in-home interview, participants were asked "During the past 12 months, that is, since (current date), have you/SP donated blood?" Those who responded "yes" were listed as having made a recent blood donation, whereas those who responded "no" were listed as not.

\section{Statistical Analysis}

Data were analyzed with SAS (version 9.3; SAS Institute Inc., Cary, NC) by using survey design variables and interview sample weights to obtain weighted frequencies. Wald-chi square tests were used to assess trends in recent blood donations by sex, age, race, household income, and education level.

\section{Results}

The overall recent blood donation rate has hovered around 6\% since 1999, with no significant change during that time period. Over the last 2 decades, 
percentage of individuals aged 20 to 29 years with a recent blood donation has increased significantly, from $5.9 \%(5.1 \%$ to $6.8 \%)$ in 1999 to 2004 to $8.4 \%$ (7.1\% to $9.7 \%$ ) in 2011 to 2016 (Table 1).

During the same time period, the percentage of individuals aged 30 to 39 years with a recent blood donation decreased significantly, from 7.0\% (5.5\% to $8.5 \%$ ) in 1999 to 2004 to $4.2 \%$ (3.3\% to $5.2 \%$ ) in 2011 to 2016 (Values in parentheses are 95\% confidence intervals for the percentages reported). During this same time period, individuals with an education of a 4-year college degree or greater also saw a significant decrease in their recent blood donation rate, from $10.7 \%$ (8.8\% to $12.6 \%)$ in 1999 to 2004 to $7.5 \%$ (6.2\% to $8.8 \%)$ in 2011 to 2016.

\section{Discussion}

Although the national blood donation rate has not changed significantly, significant changes in donation rates have occurred among a number of US subpopulations. In addition, significant racial and disparities in blood donation rates exist within the US adult population. Further research is necessary to determine the implications these rates and disparities in donation may have on the future of US blood supply. ${ }^{5}$ Our analysis is limited in that the NHANES data are cross-sectional; therefore, we cannot draw direct conclusions on the trends in blood donation. In addition, the United States has strict guidelines that limit blood donation among populations of individuals with certain medical conditions, intravenous drug users, and those who engage in certain types of sexual behavior. Due to the na- ture of NHANES, we are unable to control for these factors.

\section{Conclusion}

This article presents the most recent available estimate of national blood donation rates across the United States, as well as disparities that exist within donation patterns.

John P. Twarog had full access to all the data in the study and takes responsibility for the integrity of the data and the accuracy of the data analysis.

To see this article online, please go to: bttp://jabfm.org/content/ 32/5/746.full.

\section{References}

1. Klein HG. Blood donor demographics and transfusion recipient survival-no country for old men? JAMA Intern Med. 2016;176:1315-6.

2. Boulware LE, Ratner LE, Ness PM, Cooper LA, Campbell-Lee S, LaVeist TA, Powe NR. The contribution of sociodemographic, medical, and attitudinal factors to blood donation among the general public. Transfusion 2002;42:669-678.

3. National Health and Nutrition Examination Survey. Questionnaires, datasets, and related documentation. Available from: http://www.cdc.gov/nchs/nhanes/ nhanes_questionnaires.htm. Accessed October 31, 2018.

4. National Center for Health Statistics. National Health and Nutrition Examination Survey: NHANES response rates and population totals. https://wwwn.cdc.gov/ nchs/nhanes/ResponseRates.aspx. Accessed October 31, 2018.

5. Benjamin RJ, Whitaker BI. Boom or bust? Estimating blood demand and supply as the baby boomers age. Transfusion 2011;51:670-673.

doi: 10.3122/jabfm.2019.05.180378

The above letter was referred to the author of the article in question, who offers the following reply. 